\title{
Benefícios no uso do suplemento creatina na hipertrofia e força
}

\author{
Benefits of use of the creatine supplement in hypertrophy and strength \\ Beneficios de usar el suplemento de creatina en hipertrofia y fuerza
}

Recebido: 25/11/2021 | Revisado: 29/11/2021 | Aceito: 30/11/2021 | Publicado: 04/12/2021

\author{
Alícia Momes Da Silva \\ ORCID: https://orcid.org/00000-0002-9945-8809 \\ Universidade Nilton Lins, Brasil \\ E-mail: aliciamomes5@gmail.com \\ Omero Martins Rodrigues Junior \\ ORCID: https://orcid.org/00000-0002-8552-3278 \\ Universidade Nilton Lins, Brasil \\ E-mail: Omeromartins.farm@gmail.com
}

\begin{abstract}
Resumo
A creatina é um composto orgânico, uma amina, e não aminoácido, e é uma substância orgânica extraída da carne. A creatina vem sendo muito pesquisada devido ao seu potencial efeito no rendimento físico de atletas envolvidos em exercícios de alta intensidade e curta duração, intermitentes e com curtos períodos de recuperação (Corrêa; Lopes, 2014). A creatina pode ser produzida pelo nosso organismo já que é formada a partir de aminoácidos não essenciais. Porém, é comum ver pessoas que praticam musculação fazendo o uso de suplementação de creatina para aumentar o desempenho nos treinos e ganhar massa muscular (Medeiros et al., 2010). Foi feito um levantamento bibliográfico com o objetivo de caracterizar e analisar informações disponibilizadas e estudos publicados sobre tema. Pesquisado por meio do banco de dados da REDALYC, LYLACS, MEDLINE, SCIELO. Os descritores utilizados para a busca foram: atleta/athletes, creatina/creatine, creatinina, hipertrofia, muscular strength, muscle power, saudável/healthy.
\end{abstract}

Palavras-chave: Suplemento alimentar; Creatina; Mecanismo de ação.

\begin{abstract}
Creatine is an organic compound, an amine, not an amino acid, and is an organic substance extracted from meat. Creatine has been much researched due to its potential effect on the physical performance of athletes involved in high intensity and short duration, intermittent exercises with short recovery periods (Corrêa; Lopes, 2014). Creatine can be produced by our body as it is made from non-essential amino acids. However, it is common to see people who practice weight training using creatine supplementation to increase performance in training and gain muscle mass (Medeiros et al., 2010).A bibliographic survey was carried out in order to characterize and analyze available information and published studies on the subject. Searched through REDALYC, LYLACS, MEDLINE, and SCIELO: atleta/athletes, creatina/creatine, creatinina, hipertrofia, muscular strength, muscle power, saudável/healthy.
\end{abstract}

Keywords: Food supplement; Creatine; Mechanism of action.

\section{Resumen}

La creatina es un compuesto orgánico, una amina, no un aminoácido, y es una sustancia orgánica extraída de la carne. La creatina se ha investigado mucho debido a su efecto potencial sobre el rendimiento físico de los deportistas que realizan ejercicios de alta intensidad y corta duración, intermitentes con cortos períodos de recuperación (Corrêa; Lopes, 2014). La creatina puede ser producida por nuestro cuerpo ya que está hecha de aminoácidos no esenciales. Sin embargo, es común ver personas que practican entrenamiento con pesas utilizando suplementos de creatina para aumentar el rendimiento en el entrenamiento y ganar masa muscular (Medeiros et al., 2010). Se realizó una encuesta bibliográfica con el fin de caracterizar y analizar la información disponible y los estudios publicados. sobre el tema. Búsqueda en las bases de datos REDALYC, LYLACS, MEDLINE, SCIELO: atleta/atletas, creatina / creatina, creatinina, hipertrofia, fuerza muscular, potencia muscular, saudável / saludable.

Palabras clave: Suplemento alimenticio; Cretino; Mecanismo de acción.

\section{Introdução}

Em 1832 houve o primeiro relato sobre creatina, sendo que Michel Chevreu foi o pioneiro a descrevê-la como elemento natural dos músculos contráteis. Todavia, somente em 1847 foi confirmada essa teoria por Justus Liebig, com um estudo que descreveu que animais selvagens (livres), tinham maior quantidade de creatina quando relacionados a animais 
criados em cativeiro, chegando a conclusão que o acúmulo dessa substancia seria produto do trabalho muscular (Leite et al., 2015).

A creatina (ácido metil guanidino acético) é um aminoácido que, além de ser encontrado em alguns alimentos, também é produzido endogenamente, por um processo que envolve órgãos como fígado, rins e pâncreas e usa como substratos outros aminoácidos (glicina, metionina e arginina) (Amaral \& Nascimento, 2020).

A combinação polipeptídica entre a glicina, arginina e metionina tem como resultado em seu metabolismo final a produção de creatina, conhecida também como ácido metilguanidina-acético. Sua síntese acontece em duas etapas: a primeira, no rim, no qual, a glicina e a arginina são transformadas com base na enzima transaminidase, dessa forma a creatina circula até o fígado para receber um grupo metil, oriundo do aminoácido metionina (Menezes, Moraes \& Linhares, 2020).

A creatina vem sendo uma suplementação muito utilizada no treinamento de força, onde sujeitos fazem o consumo durante protocolos de treinamento, objetivando ganhos de força, hipertrofia e potência muscular (Corrêa, 2013).

A partir dos Jogos Olímpicos de Barcelona no ano de 1992, o uso de creatina como suplementação se popularizou e hoje em dia é um dos mais conhecidos suplementos proteicos utilizados pelos atletas e por quem pratica atividade física (Carvalho; Molina; Fontana, 2011).

A creatina vem sendo uma suplementação muito utilizada no treinamento de força, onde sujeitos fazem o consumo durante protocolos de treinamento, objetivando ganhos de força, hipertrofia e potência muscular (Corrêa, 2013).

Para Batista et al. (2010), os suplementos ergogênicos tem por objetivo aumentar o tecido muscular, promove a produção de energia no músculo, diminui a fadiga e a redução de lipídio corporal. A creatina é um desses suplementos nutricionais, o qual é utilizada por quem busca performance ou somente estética.

Para Gualano et al. (2010), há indícios que, mesmo quando não se executa treinamento de força, a creatina como suplemento pode ser benéfica na força muscular, devido diversos mecanismos, como aumentar a fosforilcreatina intramuscular, sendo que assim a mesma se regenera com maior velocidade durante o exercício, o tamponamento dos íons $\mathrm{H}+$ melhora a atividade da via glicólica, melhora da atividade da bomba sarcoplasmática de cálcio devido a diminuição do período de relaxamento do músculo esquelético, maior concentração na musculatura de glicogênio, são alguns fatores, porem dentre todos esses os dois primeiros se destacam mais em relação a melhora aguda de desempenho. Os autores ressaltam ainda uma pesquisa feita com indivíduos que receberam creatina e um outro grupo cujo qual recebeu placebo; porém, os dois grupos desempenhando a mesma carga integral em seu treinamento. Estes grupos reagiram da mesma forma ao programa de treinamento visando força e hipertrofia, assim associa os benefícios da creatina ao aumento do volume de treino. Desta forma, é sugerido através destes estudos que os efeitos da creatina como suplementação, age sobre a hipertrofia dependendo da capacidade do mesmo em evoluir o volume de treino.

Em uma análise literária feita por Nemezio, Oliveira e Silva (2015), subentende a eficácia do suplemento ao aumentar o conteúdo intramuscular de creatina, elevar a capacidade de resistência em uma atividade predominantemente anaeróbia, diminuir a perda de desempenho de uma série e outra de exercícios intermitentes de grande intensidade. Porém, considerando as pesquisas que objetivam aproximar os protocolos de exercício a realidade dos esportes, não foi possível obter resultados claros da verdadeira vantagem da suplementação de creatina em aprimorar o desempenho esportivo.

Avaliar a importância do uso deste suplemento Creatina, apresentar seu Mecanismo de ação, apresentar melhoria na composição corporal, como na redução no percentual de gordura e no aumento de massa magra, ou seja, hipertrofia muscular.

\section{Metodologia}

Avaliar através de uma revisão Integrativa, o uso dos suplementos alimentares em praticantes de musculação, que visam hipertrofia muscular. (Vieira, 2015). Revisão de literatura para investigar os efeitos da suplementação sobre a 
composição corporal de praticantes de exercícios físicos. (Cardoso, 2017). Levantamento na literatura científica sobre a eficácia da suplementação de creatina no ganho de força hipertrofia muscular em treinamento de força.

Quanto ao procedimento, a pesquisa foi bibliográfica onde é desenvolvida a partir de material publicado, constituído principalmente de livros e artigos em periódicos, fazendo parte também da revisão da literatura as monografias, dissertações e teses (Lakatos \& Marconi, 2010).

A metodologia é a aplicação de procedimentos e técnicas que devem ser observadas para a construção do conhecimento, com o propósito de comprovar sua validade e utilidades nos diversos lugares da sociedade (Prodanov \& Freitas,2013).

A coleta de dados foi totalmente eletrônica por meio da internet, no qual será norteada pelas palavras chaves envolvidas na temática estudada como: uso da creatina no treinamento de força; suplementação e treinamento; efeitos da creatina no treinamento de força e condicionamento físico; características da creatina.

Pesquisado por meio do banco de dados da REDALYC, LYLACS, MEDLINE, SCIELO, publicações a partir de 2011, e livros disponibilizados no Google Books, onde todo material pesquisado será analisado e revisados e contará com visões e opiniões de especialistas da área, também foram analisados alguns livros envolvendo a temática abordada.

Para análise dos dados foi utilizada abordagem qualitativa onde a aplicação desse método considera que há uma relação dinâmica entre o mundo real e o objeto de pesquisa, que não pode ser traduzido em números.

A partir da leitura bibliográfica e seletiva, foi selecionado todo conteúdo que norteará a temática abordada para o desenvolvimento teórico da pesquisa. Utilizando a técnica de fichamento, toda teoria e autores selecionados foram elencados objetivando melhor compreensão e análise da temática em questão.

Os critérios de inclusão utilizados serão: publicações a partir de 2011; publicações em Língua Portuguesa; publicações da REDALYC, SCIELO, somente livros e periódicos. Os critérios de exclusão utilizados serão: publicações menos de 10 anos; publicações em língua estrangeiras; materiais como TCC; dissertações, teses, trabalhos.

Os dados selecionados foram apresentados em forma de texto descritivo, reunindo todos os autores selecionados acerca da temática de pesquisa.

\section{Resultados e Discussão}

A pesquisa dos artigos foi pesquisado por meio do banco de dados da REDALYC, LYLACS, MEDLINE, SCIELO, utilizando dois conjuntos de intercessão de termos de busca bibliográfica: hipertrofia muscular e força no uso da suplementação creatina. A maioria dos estudos demonstrou que a suplementação de creatina, apresentou resultados positivos no desempenho anaeróbico, aumento nos percentuais de força máxima, diminuição da fadiga e aumento da massa magra. Seu uso parece ser mais eficaz em exercícios de alta intensidade, curta duração com pequenos intervalos entre as séries.

Segundo (Brasil, 2020) para utilização do suplemento alimentar, é preciso a leitura do rótulo dos produtos pelo Nutricionista é prática indispensável, já que esses produtos são utilizados como complemento aos alimentos já prescritos. Para que o uso dos suplementos proteicos seja benéfico ao usuário, a veracidade do rótulo deve ser avaliada. 
Quadro 1. Efeitos da suplementação de creatina no desempenho.

\begin{tabular}{|c|c|c|c|c|}
\hline Autor/ ano & Objetivo de estudo & Intervenção & Periodo & Principais Resultados \\
\hline $\begin{array}{c}\text { Bouzas, e } \\
\text { outros, } \\
2015 .\end{array}$ & $\begin{array}{lr}\text { Revisão sistemática para } \\
\text { investigar as formas de } \\
\text { comercialização, } & \text { as } \\
\text { prevalências de consumo e os } \\
\text { efeitos do uso de creatina. }\end{array}$ & $\begin{array}{l}\text { A prevalência de consumo varia } \\
\text { de } 10 \% \text { a } 89 \% \text { em estudos } \\
\text { recentes. Protocolo de } \\
\text { suplementação prevê uma fase de } \\
\text { sobrecarga, seguida da fase de } \\
\text { manutenção. }\end{array}$ & $\begin{array}{l}\text { As bases de pesquisa são } \\
\text { PubMed/Medline e Scielo para } \\
\text { detectar artigos publicados em } \\
\text { língua portuguesa e inglesa no } \\
\text { período de } 2007 \text { a } 2013 \text {. }\end{array}$ & $\begin{array}{l}\text { As evidências apontam que a } \\
\text { creatina pode ser um recurso } \\
\text { ergogênico eficiente e relativamente } \\
\text { seguro, desde que o seu uso seja } \\
\text { orientado por profissional } \\
\text { habilitado. }\end{array}$ \\
\hline Faria,2018 & $\begin{array}{l}\text { Levantamento na literatura } \\
\text { científica sobre a eficácia da } \\
\text { suplementação de creatina no } \\
\text { ganho de força e hipertrofia } \\
\text { muscular em praticantes de } \\
\text { treinamento de força. }\end{array}$ & $\begin{array}{l}\text { Os participantes }(\mathrm{n}=18) \text { foram } \\
\text { divididos em } 2 \text { grupos (creatina } \mathrm{x} \\
\text { placebo). Indivíduos receberam } \\
\text { treinamento de força por } 8 \\
\text { semanas, } 30 \mathrm{~g} / \mathrm{dia} \text { de creatina } \\
\text { monoidratada ou placebo na } \\
\text { terceira semana de treinamento a a } \\
\text { partir da quarta até a oitava semana } \\
5 \text { g/dia. }\end{array}$ & $\begin{array}{l}\text { Foi realizado levantamento } \\
\text { bibliográfico, baseado em artigos } \\
\text { científicos obtidos nas bases de } \\
\text { dados da Biblioteca Virtual em } \\
\text { Saúde (Bvs), no portal Scientific } \\
\text { Eletronic Library Online } \\
\text { (Scielo), Lilacs, Bireme e } \\
\text { Pubmed. }\end{array}$ & $\begin{array}{l}\text { Suplementação de creatina deve ser } \\
\text { realizada com cautela pelo } \\
\text { profissional da saúde, sendo } \\
\text { necessário uma avaliação criteriosa } \\
\text { levando em consideração às } \\
\text { necessidades e particularidades de } \\
\text { cada indivíduo, o tipo de atividade } \\
\text { física, a dose a ser utilizada e tempo } \\
\text { de duração da suplementação. }\end{array}$ \\
\hline $\begin{array}{l}\text { Cardoso } \\
\mathrm{e} \\
\text { outros, } 20 \\
17\end{array}$ & $\begin{array}{l}\text { Revisão de literatura para } \\
\text { investigar os efeitos da } \\
\text { suplementação de creatina } \\
\text { sobre a composição corporal de } \\
\text { praticantes de exercícios } \\
\text { físicos. }\end{array}$ & $\begin{array}{l}\text { O protocolo de suplementação foi } \\
\text { distinto nos estudos variando de } 3 \mathrm{~g} \\
\text { a } 430 \mathrm{~g} \text { tendo períodos entre seis } \\
\text { dias a } 12 \text { dias. } \mathrm{O} \text { protocolo } \\
\text { de suplementação foi distinto nos } \\
\text { estudos variando de } 3 \mathrm{~g} \text { a } 430 \mathrm{~g} \\
\text { tendo períodos entre seis dias a } 12 \\
\text { dias. }\end{array}$ & $\begin{array}{l}\text { Foram analisados } 26 \text { artigos, } 9 \\
\text { excluídos, sendo composta por } \\
17 \text { artigos originais nacionais e } \\
\text { internacionais, uma legislação e } \\
\text { uma pesquisa em um livro, } \\
\text { publicados entre os anos de } 2000 \\
\text { a } 2014 \text {. }\end{array}$ & $\begin{array}{l}\text { A maioria dos estudos demonstrou } \\
\text { que a suplementação de creatina } \\
\text { apresentou resultados positivos no } \\
\text { desempenho anaeróbio, aumento nos } \\
\text { percentuais de força máxima, } \\
\text { diminuição da fadiga e aumento da } \\
\text { massa magra. Seu uso parece ser } \\
\text { mais eficaz em exercícios de alta } \\
\text { intensidade, curta duração com } \\
\text { pequenos intervalos entre as séries. }\end{array}$ \\
\hline $\begin{array}{l}\text { Vieira e } \\
\text { outros, } \\
2015 .\end{array}$ & $\begin{array}{l}\text { Avaliar, através de uma } \\
\text { revisão, o uso de } \\
\text { suplementos alimentares, em } \\
\text { praticantes de musculação, que } \\
\text { visam hipertrofia muscular. }\end{array}$ & $\begin{array}{l}\text { O número de praticantes de } \\
\text { musculação em cada estudo } \\
\text { apresentou o uso de suplementos } \\
\text { alimentares que variou de } 18 \text { a } \\
1.102 \text { jovens e adultos, com idade } \\
\text { entre } 18 \text { a } 59 \text { anos, com } \\
\text { predominância } \\
\text { masculino. }\end{array}$ & $\begin{array}{l}\text { A pesquisa dos artigos foi } \\
\text { realizada nas bases de dados } \\
\text { SciELO, PubMed, Science Direct } \\
\text { e BIREME utilizando-se dois } \\
\text { conjuntos de intersecção de } \\
\text { termos de busca bibliográfica: } \\
\text { hipertrofia } \\
\text { suplementação muscular e } \\
\text { nutricional. }\end{array}$ & $\begin{array}{l}\text { A utilização de suplementos } \\
\text { alimentares em praticantes de } \\
\text { musculação foi bastante elevada, } \\
\text { principalmente entre os homens, } \\
\text { utilizando para isso suplementos } \\
\text { proteicos, sendo os educadores } \\
\text { físicos, os principais responsáveis } \\
\text { pela indicação do suplemento. }\end{array}$ \\
\hline $\begin{array}{l}\text { Araújo e } \\
\text { outros, } \\
2009 .\end{array}$ & $\begin{array}{l}\text { Revisar o metabolismo da } \\
\text { creatina e os efeitos de sua } \\
\text { suplementação na força e na } \\
\text { composição corporal em } \\
\text { indivíduos em treinamento de } \\
\text { força. }\end{array}$ & $\begin{array}{l}\text { Os protocolos mais utilizados estão } \\
\text { baseados por: 20-30g / dia } \\
\text { (período de sobrecarga) seguidos } \\
\text { por 2-5g/dia (período de } \\
\text { manutenção) ou } 0,3 \mathrm{~g} / \mathrm{kg} / \mathrm{dia} \\
\text { (período de sobrecarga) seguidos } \\
\text { por } 0,03 \mathrm{~g} / \mathrm{kg} / \mathrm{dia} \text { (período de } \\
\text { manutenção). }\end{array}$ & $\begin{array}{l}\text { Fontes variadas como Revista } \\
\text { Brasileira de Medicina do } \\
\text { Esporte e Revista de Nutrição. }\end{array}$ & $\begin{array}{l}\text { Concluímos que pesquisas adicionais } \\
\text { controladas devem ser realizadas, em } \\
\text { populações diversas, na tentativa de } \\
\text { melhor esclarecer os mecanismos } \\
\text { pelos quais a suplementação de } \\
\text { creatina pode beneficiar a massa } \\
\text { muscular e força muscular. }\end{array}$ \\
\hline $\begin{array}{l}\text { Vargas e } \\
\text { outros, } \\
2010 \text {. }\end{array}$ & $\begin{array}{l}\text { Verificar, por meio de uma } \\
\text { revisão sistemática, os } \\
\text { possíveis efeitos ergogênicos } \\
\text { da suplementação de creatina } \\
\text { no treinamento de força. }\end{array}$ & $\begin{array}{l}\text { A dosagem utilizada na maioria } \\
\text { dos estudos foi de } 20 \mathrm{~g} \text { de creatina } \\
\text { dividida em quatro doses durante } \\
\text { os cinco primeiros dias e } 2 \mathrm{~g} \text { a } 5 \mathrm{~g} \\
\text { por dia no restante do estudo. }\end{array}$ & $\begin{array}{l}\text { Foi realizada revisão sistemática } \\
\text { em artigos nacionais e } \\
\text { internacionais dos últimos dez } \\
\text { anos. Foram analisados } 26 \\
\text { artigos, sendo } 8 \text { revisões e } 18 \text { de } \\
\text { campo, pesquisadas em revistas } \\
\text { na área de saúde. }\end{array}$ & $\begin{array}{l}\text { Os resultados encontrados nos } \\
\text { estudos sugerem que a } \\
\text { suplementação de creatina, utilizada } \\
\text { de maneira correta, pode levar a } \\
\text { ganhos significativos na performance } \\
\text { de atletas durante o trabalho de alta } \\
\text { intensidade e curta duração em } \\
\text { treinamentos de longa duração. }\end{array}$ \\
\hline $\begin{array}{l}\text { Panta e } \\
\text { Silva } \\
\text { Filho, } \\
2015 .\end{array}$ & $\begin{array}{l}\text { Estudo de revisão sistemática } \\
\text { para verificar através de } \\
\text { ensaios clínicos, os efeitos da } \\
\text { suplementação de creatina na } \\
\text { força muscular de praticantes } \\
\text { de musculação. }\end{array}$ & $\begin{array}{l}\text { Em } 05 \text { dos ensaios clínicos a } \\
\text { suplementação foi feita de maneira } \\
\text { de saturação, onde se administra } \\
\text { uma carga maior da substância, } \\
\text { podendo variar de } 20 \text { a } 30 \mathrm{~g} \text { diária, } \\
\text { divididos entre } 4 \text { a } 5 \text { vezes ao dia } \\
\text { em porções de } 4 \text { a } 5 \mathrm{~g} \text { e logo após } \\
\text { uma fase de manutenção que vai } \\
\text { até o final da pesquisa onde se } \\
\text { suplementa com apenas } 3 \text { a } 5 \mathrm{~g} \\
\text { diárias, na maioria dos casos pós- } \\
\text { treino. }\end{array}$ & $\begin{array}{l}\text { Realizaram -se filtros nas } \\
\text { principais bases de dados: Scielo; } \\
\text { Pubmed, e no site de busca } \\
\text { Scholar Google, por haver } \\
\text { diversos artigos que não estão } \\
\text { indexadas nas bases supracitadas. }\end{array}$ & $\begin{array}{l}\text { A suplementação de creatina mostrou } \\
\text { aumentar de forma significativa à } \\
\text { força muscular em praticantes de } \\
\text { musculação. }\end{array}$ \\
\hline
\end{tabular}




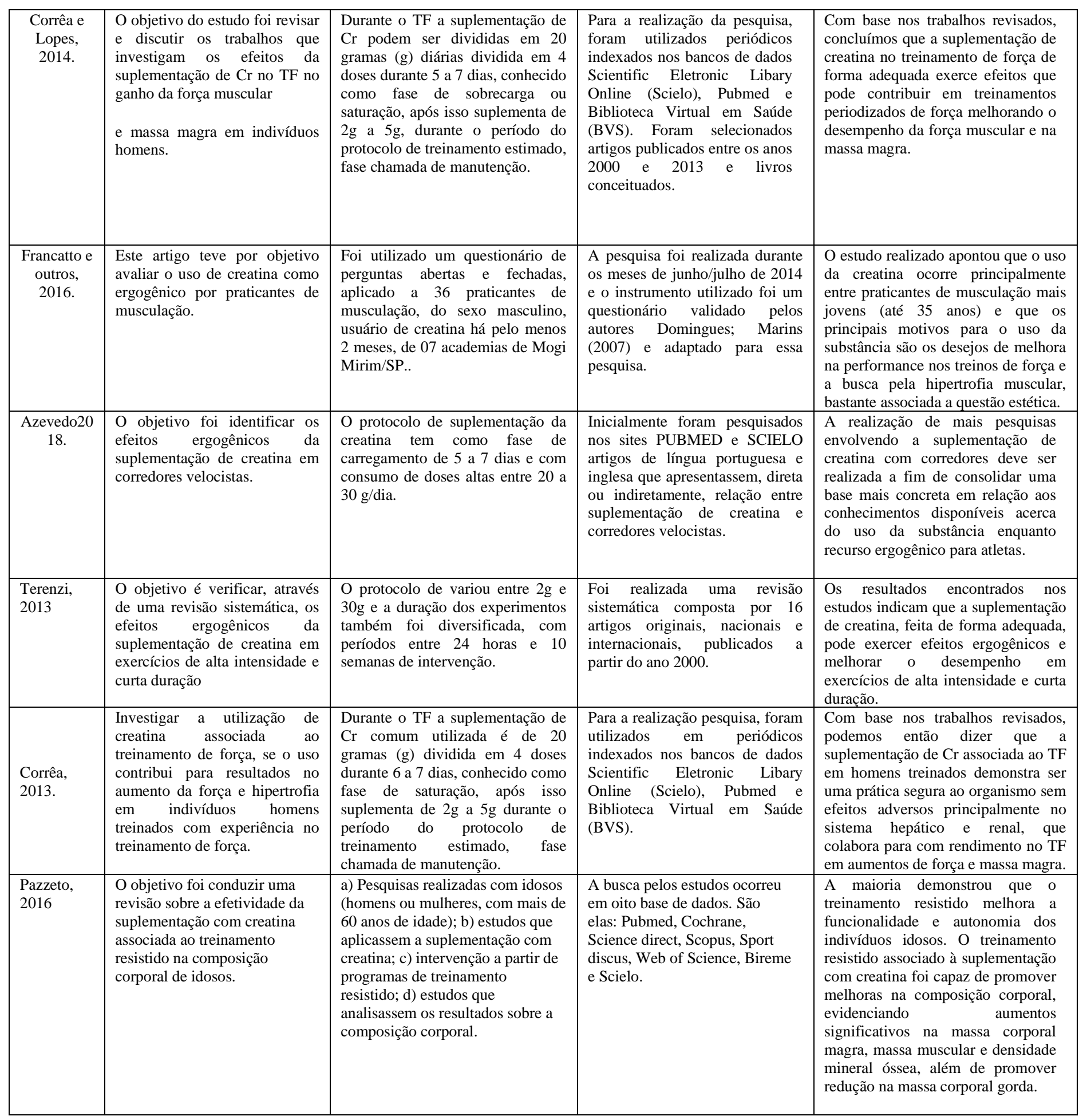

Fonte: Francatto et al. (2016).

\subsection{Mecanismo de Ação da Creatina no esporte}

A creatina é um composto orgânico derivado dos aminoácidos L-arginina, Lmetionina e L glicina. Pode ser sintetizada no organismo através de rins, fígado ou pâncreas ou pode ser obtida através da ingestão de alguns alimentos.

(Vargas et al., 2010). 
A suplementação de creatina é bastante usada por esportistas para aumentar o desempenho atlético, melhorando o suprimento de energia para os tecidos musculares. É também um composto cerebral essencial que ajuda a cognição melhorando o suprimento de energia e a neuroproteção (Avgerinos et al.,2018).

Atualmente, é um dos suplementos mais estudados entre o meio acadêmico. Sendo incontestável a sua funcionalidade em diversos estudos já apresentados.

A creatina ligada ao grupamento fosfato (creatina fosfato ou fosfocreatina), atua no músculo esquelético onde serve de reservatório para gerar energia, sendo a principal responsável por doar fosfato para adenosina disfosfato (ADP), com o intuito de gerar ATP.

\subsection{Fontes Alimentares}

Apesar de ser bastante suplementada, e ainda ser produzida pelo nosso organismo, uma vez que é formada por aminoácidos não essenciais, vale ressaltar que é possível adquirir a creatina através de uma alimentação rica em proteína animal (Corrêa; Lopes, 2014).

Segundo Stábile (2017), a creatina pode ser adquirida pelo consumo de carnes vermelha e peixes, onde possui entre 2 a $5 \mathrm{~g} \mathrm{em} 1 \mathrm{Kg}$.

A Tabela 1 apresenta as principais fontes alimentares de creatina, bem como suas quantidades em $\mathrm{g} / \mathrm{kg}$ de peso do alimento.

Tabela 1 - Alimentos fontes de Creatina.

\begin{tabular}{cc}
\hline Alimento & Creatina g/kg \\
\hline Linguado & 2 \\
Salmão & 4,5 \\
Bacalhau & 3 \\
Carne Bovina & 4,5 \\
Carne Suína & 5 \\
\hline
\end{tabular}

Fonte: Alves (2002).

\subsection{Creatina e CHO}

O CHO é considerado um dos principais nutrientes no meio esportivo. Boa parte dos atletas atualmente consomem bastante por ser uma das principais fontes de energia para a realização de atividades físicas. Segundo Oliveira (2014), o uso de $\mathrm{CHO}$ em exercícios como o treinamento de força, tem sido essencial tanto para melhorar o rendimento esportivo nos treinos como para ajudar na hipertrofia muscular.

A relação da Creatina com o $\mathrm{CHO}$ vem sendo bastante estudada, pois estudos tem comprovado a melhora na absorção da Creatina relacionado com uma refeição rica em CHO (Kreider et al. 2017).

Um estudo recente realizado por Theodorou et al. (2017) no Reino Unido, buscou investigar se a ingestão de creatina juntamente com carboidratos afetava a absorção e a retenção de creatina no corpo. Para a realização do estudo, foram recrutados 24 voluntários do sexo masculino ativos, que foram divididos em dois grupos. O grupo A ingeriu uma solução com apenas 5 gramas de creatina, já o grupo B ingeriu uma solução com 5 gramas de creatina, mais 93 gramas de carboidratos simples 30 minutos após a ingestão da creatina. Os voluntários ingeriram as respectivas soluções 4 vezes por dia, durante 5 dias. 
Os resultados de Theodorou et al. (2017), revelaram que a suplementação resultou num aumento dos níveis de fosfocreatina muscular, e creatina nos grupos A e B, mas os níveis de creatina aumentaram em mais $60 \%$ no grupo B comparado ao grupo A. Vale ressaltar que houve diminuição da excreção urinária de creatina nos indivíduos participantes do grupo B.

A suplementação de creatina sozinha não teve qualquer efeito sobre a concentração de insulina, porém, a ingestão de creatina associada ao carboidrato aumentou os níveis desse hormônio de maneira significativa. As descobertas encontradas demonstram que a ingestão de carboidratos aumenta a creatina muscular de forma substancial durante a ingestão de creatina (Theodorou et al. 2017).

\subsection{Resultados na força e hipertrofia muscular}

A quantidade de fosfocreatina (CP) é provavelmente um dos fatores mais importantes para a fadiga muscular depois que você pratica um exercício de alta intensidade e de curta duração. Por isso, sua utilização como forma de suplemento energético baseia-se justamente na teoria de que, com um maior estoque dessa substância dentro do músculo, nós conseguimos manter uma potência muscular máxima durante um período maior de tempo (Oliveira et al., 2017).

Estudo realizado por Batista et al. (2012), desenvolvido em uma academia de ginástica da cidade de Goiânia, utilizou uma amostra composta por 20 homens, divididos de forma aleatória em dois grupos: Grupo Experimental (GE) e Grupo Controle (GC). Foram utilizados como critérios de exclusão, os indivíduos com limitações físicas e que estivessem uso de outro tipo de ergogênico, seja suplemento nutricional ou farmacológico.

Dez indivíduos usaram a suplementação de creatina durante os treinos (Grupo Experimental) por via oral e dez não foram suplementados, mas participaram do treinamento de força (Grupo Controle), durante o período do estudo de três semanas. A dosagem foi de $20 \mathrm{~g} /$ dia durante seis dias e de 2 a $5 \mathrm{~g} /$ dia durante três semanas. Todos os indivíduos realizaram o mesmo treino, com uma frequência de três a quatro vezes por semana, controlado pelo próprio pesquisador.

Já outro estudo realizado por Medeiros et al. (2010), no período de seis dias com 27 mulheres fisicamente ativas, com idade de 23 anos, sendo utilizando $20 \mathrm{~g}$ de creatina diariamente, foi verificado no final do estudo que a suplementação de creatina aumentou significativamente a força, com incrementos de 7,85\%,7,31\% e 5,52\% para a primeira, segunda e terceira séries, respectivamente.

Passado o período da avaliação, observou-se os efeitos do treinamento e da suplementação após as três semanas, os autores observaram que o grupo experimental (suplementado com creatina) apresentou ganhos significativos na massa corporal. Já o outro grupo controle, o qual foi submetido apenas ao treinamento de força, apresentou ganhos de perímetros e na redução de gordura, porém as alterações não foram significativas. (Batista et al., 2012).

\section{Considerações Finais}

Creatina desempenha papel fundamental no meio esportivo e tem se tornado um dos suplementos mais procurados por praticantes de atividade física. Boa parte dessa imensa procura e interesse pelo o suplemento é a comprovação da sua eficácia em muitos estudos apresentados, já que é um dos suplementos mais estudados atualmente.

É importante destacar que apesar de toda a comprovação da sua capacidade, a Creatina ainda é alvo de vários questionamentos, principalmente a respeito dos possíveis efeitos colaterais. Vale ressaltar que de todos os estudos apresentados, nenhum se destacou por apresentar possíveis efeitos e malefícios que de alguma forma possa prejudicar o usuário. 
Necessário ressaltar sobre o "Ciclo de Saturação" onde alguns estudos destacaram que ao ser administrado doses de $0,3 \mathrm{~g} / \mathrm{kg} /$ dia durante $5-7$ dias e seguido de uma dose de manutenção variando de $3-5 \mathrm{~g} /$ dia durante $3-4$ semanas, mostrou-se eficiente e com resultados positivos na performance dos atletas apresentados. Porém é sempre importante destacar a individualidade de cada pessoa, e que a intensidade das atividades, estilo e hábitos devem ser considerados.

Contudo, alguns estudos mostram que esta suplementação pode ser interessante para outas questões, entre elas a preservar a massa muscular em idosos e prevenir doenças como Parkinson, Huntington e Alzheimer, existe a possibilidade de o consumo do suplemento de creatina causar alguns efeitos colaterais, um deles é a retenção de líquidos. A creatina é osmoticamente ativa, provoca aumento de seu conteúdo intracelular na forma de creatina livre e creatina fosfato no músculo, isso pode induzir um influxo de água para dentro da célula muscular, aumentando a água intracelular, o que pode dar uma falsa sensação de ganho de massa muscular.

É importante saber que consumir a creatina não aumenta a massa muscular (é preciso malhar para conseguir isso). Basicamente, o que o suplemento faz é elevar a tolerância do atleta ao esforço e retardar a fadiga, permitindo que ele use cargas maiores e tenha um melhor desempenho nos exercícios o que consequentemente vai gerar ganhos maiores. Além disso, por ser armazenada nos músculos juntamente com a água, a substância leva a um aumento do volume muscular.

Por fim, com base nos estudos citados no presente trabalho pode-se concluir que parece não existir risco ou maléfico a saúde quando a suplementação de creatina é feito da maneira bem administrada, e que este suplemento continua se destacando por ser responsável por aumentar de forma significativa à força muscular e a hipertrofia em praticantes de musculação.

Portanto, é importante ressaltar que a suplementação deve ser prescrita por um profissional habilitado, levando em consideração o tipo de atividade física, duração e condições fisiológicas do mesmo.

\section{Referências}

Amaral.A, de S. \& Nascimento.O.V.(2020). Efeitos de suplementação de creatina no desempenho humano.uma revisão de literatura. (4).

Avgerinos, K. I. et al. (2018) Effects of creatine supplementation on cognitive function of healthy individuals: a systematic review of randomized controlled trials. experimental gerontology, (108), 166-173.

Batista, J. A. et al. (2012) Suplementação de creatina e treinamento de força: alterações antropométricas e na resultante força máxima. revista eletrônica saúde e ciência, 5(8),22-31.

Brasil, C. C. B. (2020), Nutrição e nálise de controle de alimentos. Atenas 3(5).

Confortin, F. G., Sá, C. A., Wildner, P. P. (2010) Avaliação da creatina associada à dextrose como suplemento nutricional ergogênico sobre a performance de atletas de futebol. revista brasileira de nutrição esportiva, 10(56),136-144.

Crisafulli, D. L. et al (2018). Creatine-electrolyte supplementation improves repeated sprint cycling performance: a double blind randomized control study. journal of the international society of sports nutrition, 15(1),1-16.

França, E. et al. (2015) Co-ingestão fracionada de bicarbonato de sódio e carboidrato aumenta a performance sem desconforto gastrointestinal. revista brasileira de nutrição esportiva, são paulo, 9(53),437-446.

Francatto, E. C., Reggiolli, M. R, Maldonado, R. R., \& de Oliveira, D. S. (2016). A utilização de creatina por praticantes de musculação em academias na cidade de Mogi Mirim- SP. Ciência \& Inovação, 3(1).

Gualano, B. et al. (2010) Efeitos da suplementação de creatina sobre força e hipertrofia muscular: atualizações. revista brasileira de medicina do esporte, $16(3), 1-59$.

Gualano, B. (2014) suplementação de creatina: efeitos ergogênicos terapêuticos e adversos, 1(156).

Islam, H., Yorgason, N. J., \& Hazell, T. J. (2015) creatine co-ingestion with carbohydrate or cinnamon extract provides no added benefit to anaerobic performance. european journal of sport science, 16(6),685-693.

Kaviani, M., Abassi, A., \& Chilibeck, P. D. (2018) Creatine monohydrate supplementation during eight weeks of progressive resistance training increases strength in as little as two weeks without reducing markers of muscle damage. the journal of sports medicine and physical fitness, 1 (12).

Kreider, R. B. et al. (2017) International society of sports nutrition position stand: safety and efficacy of creatine supplementation in exercise, sport, and medicine. journal of the international society of sports nutrition, 14(1),1-18. 
Research, Society and Development, v. 10, n. 16, e136101623886, 2021

(CC BY 4.0) | ISSN 2525-3409 | DOI: http://dx.doi.org/10.33448/rsd-v10i16.23886

Lakatos, E. M., \& Marconi, M. A. (2010). Fundamentos de Metodologia Científica .(7a ed), atlas.

Medeiros, R. J. D. et al. (2010) Efeitos da suplementação de creatina na força máxima e na amplitude do eletromiograma de mulheres fisicamente ativas. revista brasileira de medicina do esporte, 16(5), 2.

Melo, A. L., Araújo, V. C., Reis, W. A. (2016) Efeito da suplementação de creatina no treinamento neuromuscular e composição corporal em jovens e idosos. revista brasileira de nutrição esportiva, 10(55),79-86.

Menezes, C. dos S., Moraes, B. A., \& Linhares, P. S. D. (2020). Creatina: efeitos da suplementação. referências em saúde da faculdade estácio de sá de goiás, $3(2)$.

Nogueira, F. R. D. et al. (2014) Dor muscular e atividade de creatina quinase após ações excêntricas: uma análise de cluster. revista brasileira de medicina do esporte, 20(4),1-5.

Oliveira, L. M., Azevedo, M. O., Cardoso, C. K. S. (2017) Efeitos da suplementação de creatina sobre a composição corporal de praticantes de exercícios físicos. revista brasileira de nutrição esportiva, 11(61),10-15.

Padilha, C. S. et al. (2016) oral creatine supplementation attenuates muscle loss caused by limb immobilization: a systematic review. fisioterapia em movimento, 30(4),831-838.

Prodanov., C. C., \& De Freitas., E. C. (2013). Metodologia do Trabalho Científico: Métodos e Técnicas da Pesquisa e do Trabalho Acadêmico.

Panta, R., \& Silva Filho, J. N. (2015) Efeitos da suplementação de creatina na força muscular de praticantes de musculação: uma revisão sistemática. revista brasileira de nutrição esportiva, 9(54)',518-524.

Pastore Neto, M. et al. (2018) Factors associated with changes in creatine phosphokinase (cpk) in trauma patients submitted to the "red wave", with evolution to rhabdomyolysis. revista do colégio brasileiro de cirurgiões, 45(2), 1-9.

Pellegrini, A. R., Corrêa, F. S. N., \& Barbosa, M. R. (2017) Consumo de suplementos nutricionais por praticantes de musculação da cidade de São Carlos -SP. revista brasileira de nutrição esportiva, 11(61), 59-73.

Theodorou, A. S., et al. (2017) the effect of combined supplementation of carbohydrates and creatine on anaerobic performance. biology of sport, 1(2), 169175 .

Vieira, T. H. M. et al. (2016) Pode a suplementação da creatina melhorar o desempenho no exercício resistido? revista brasileira de nutrição esportiva, 10(55), 3-10. 